\title{
Effect of Cage Configuration in Structural and Optical Properties of TiN Films Grown by Cathodic Cage Discharge
}

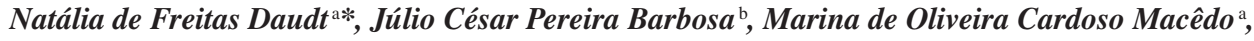 \\ Marcelo Barbalho Pereira ${ }^{\mathrm{c}}$, Clodomiro Alves Junior ${ }^{\mathrm{a}}$ \\ a Programa de Pós-graduação em Ciência e Engenharia dos Materiais, Universidade Federal do Rio \\ Grande do Norte - UFRN, CEP 59072-970, Natal, RN, Brazil \\ ${ }^{\mathrm{b}}$ Universidade Federal Rural do Semi-Árido - UFERSA, CEP 59625-900, Mossoró, RN, Brazil \\ 'Universidade Federal do Rio Grande do Sul - UFRGS, CEP 91501-970, Porto Alegre, RS, Brazil
}

Received: October 17, 2012; Revised: December 17, 2012

\begin{abstract}
Cathodic cage discharge was developed recently in order to eliminate phenomena as edge effect and overheating, which occurs during conventional processes. In this study, the effect of cage configuration in active species during the deposition process and optical properties of TiN film were studied. TiN compound was chosen because its optical properties are very sensitive to slight variations in microstructure and film thickness, becoming a good monitoring tool in fabrication process control. Cages were made of titanium and have different holes numbers and holes diameter. Electrical efficiency of the system and optical properties of TiN films were strongly influenced by experimental conditions. It was found that with more holes at the top of cage, deposition rate and crystallinity were higher, if compared to cages with a small number of holes at the top. On the other hand, the opposite behavior was observed when more holes were located at the sidewall of cage.
\end{abstract}

Keywords: cathodic cage, thin films, titanium nitride, Optical Emission Spectroscopy, plasma deposition, optical properties

\section{Introduction}

Cathodic cage plasma technique was recently developed in order to eliminate edge effect and overheating, which occurs during thermochemical treatment with plasma. These effects take place due to high superficial area/ volume ratio, mainly in pieces with complex geometry ${ }^{1-3}$. The literature reports provided evidence that cathodic cage reduce the edge effect in steel samples ${ }^{3,4}$, improve the temperature distribution throughout the sample and allow the nitriding of pieces with different dimensions ${ }^{1}$. The most recent researches have been regarding the efficiency of cathodic cage in order to modify surfaces of titanium alloys ${ }^{5}$, polymer ${ }^{6}$ and deposit silver particles on stainless steel substrates ${ }^{7}$.

This technique is used to protect electrically the workpiece during the process, resembling a Faraday cage device. An isolator is placed between the workpiece and the cathode, in order to keep the workpiece in a floating potential $^{4}$. In this configuration, only the cage is in cathodic potential, producing a hollow cathode effect in each hole. Due to the higher density of ions formed in the holes of the cage; there is a higher sputtering rate in that region. The combinations of the gas species with the sputtered species present in plasma are directed towards the substrate surface, where they are deposited and diffused onto the sample ${ }^{8}$. Thus, it is possible to produce a hybrid process of deposition and diffusion. Furthermore, the literature reported by Nishimoto ${ }^{9}$ and Sousa ${ }^{10}$ provided evidence that the distance

*e-mail: daudt.natalia@gmail.com between the sample and cage influence in the properties of the nitrited sample, since nitrited layer thickness increased as the distance between sample and cage decreased.

Optical properties of titanium nitride films are very sensitive to even small variations in chemical composition and thickness. Therefore, this sensibility is a useful tool to monitoring the fabrication process control. Moreover, titanium nitride films are used in various industrial applications, for example, as coatings for high hardness and low friction in metallurgical industry ${ }^{11}$, decorative coatings replacing gold, since different color tones may be achieved varying $\mathrm{Ti} / \mathrm{N}$ ratio $^{12}$, as well as coatings for solar cells, solar control windows ${ }^{13}$, biomaterials ${ }^{14}$ and microelectronic semiconductors ${ }^{15}$.

Because this technique was developed recently, there are few studies about the effect of process parameters on the characteristics of the grown film. Therefore, this study proposed to investigate the efficiency of this technique to obtain TiN thin films on glass substrates. The effects of cage configuration on the deposition rate, electrical parameters, microstructure, topography and optical properties of the grown film were determined by Optical Emission Spectroscopy (OES), Atomic Force Microscopy (AFM), $\mathrm{X}$-Ray Diffraction, Spectrophotometry and Ellipsometry.

\section{Material and Methods}

Rectangular samples of borosilicate glass (each with $25 \times 10 \mathrm{~mm}^{2}$ surface area and $2 \mathrm{~mm}$ thickness) were used as substrate in this study. The chemical composition of 
borosilicate glass was $72.1 \%$ of silicon dioxide, $14.3 \%$ of sodium oxide, $6.3 \%$ of calcium oxide, $4.1 \%$ of magnesium oxide, $1.1 \%$ of aluminum oxide, $1.1 \%$ of potassium oxide and $1.0 \%$ of other oxides. The deposition process was conducted in an ion nitriding reactor adapted to cathodic cage configuration. The substrates were in a floating potential because they were electrically isolated from the cathode trough an alumina disc, as illustrated in Figure 1.

The cages were made of commercially pure titanium (grade II), they have $1 \mathrm{~mm}$ of thickness and $70 \mathrm{~mm}$ of diameter. Five different cages were used and denominated as $\mathrm{L}_{1} \mathrm{~T}_{4} \mathrm{~F}_{12}, \mathrm{~L}_{1} \mathrm{~T}_{8} \mathrm{~F}_{12}, \mathrm{~L}_{2} \mathrm{~T}_{4} \mathrm{~F}_{12} \mathrm{~L}_{2} \mathrm{~T}_{8} \mathrm{~F}_{12}$ and $\mathrm{L}_{1} \mathrm{~T}_{8} \mathrm{~F}_{8}$. The $\mathrm{L}$ is referent to the number of holes lines in the sidewall of cage and $\mathrm{T}$ is referent to the number of holes lines in the top (covering) of the cage and $\mathrm{F}$ referent to hole diameter in millimeter. Table 1 shows the experimental conditions.

Pressure, temperature and duration time were fixed at 1.5 mbar, $450{ }^{\circ} \mathrm{C}$ and 120 minutes, respectively. The plasma atmosphere was compounded by $50 \%$ of Ar, $37.5 \%$ of $\mathrm{N}_{2}$ and $12.5 \%$ of $\mathrm{H}_{2}$. Argon was used to increase the titanium sputtering rate and to control nitriding rate of the cage ${ }^{16}$. Hydrogen was used to reduce the presence of superficial oxides and to increase process efficiency ${ }^{17}$.

The deposition process was monitored by Optical Emission Spectroscopy (OES), using an Ocean Optics USB 4000 spectrograph. The X-Ray Diffraction analyses were performed with a Shimadzu XRD-6000 diffractometer using $\mathrm{Cu}$ radiation $\mathrm{K} \alpha$ and an accessory for Grazing Incidence X-ray Diffraction (GIXRD) and angle of incidence fixed at $0.5^{\circ}$. The grown films were also analyzed by Atomic Force Microscopy (AFM) in contact mode with a Shimadzu microscope model SPM 9600. Optical properties were analyzed by transmittance, reflectance using a Varian Cary-5000 spectrophotometer with integration sphere. Dispersion curves, $\mathrm{n}(\lambda)$ and $\mathrm{k}(\lambda)$, were obtained by spectral ellipsometry, using Sopra GES-5E Spectral Ellipsometer.

\section{Results and Discussion}

Figure 2 shows a typical OES spectrum obtained during cathodic cage deposition at the $\mathrm{L}_{1} \mathrm{~T}_{8} \mathrm{~F}_{12}$ configuration, where some lines corresponding to $\mathrm{Ar}, \mathrm{H}_{2}$ and $\mathrm{N}_{2}$ transitions are highlighted.

The intensities lines relative to $\arg o n(750.3 \mathrm{~nm})$ of $\mathrm{N}_{2}^{+}, \mathrm{N}_{2}$ and $\mathrm{H} \alpha$ species, with respective emissions lines at $391.4 \mathrm{~nm}, 337 \mathrm{~nm}$ and $656.3 \mathrm{~nm}$ and the powder supplied at different cage configurations are shown in Figure 3. The $\mathrm{H} \alpha$ and $\mathrm{N}_{2}{ }^{+}$intensities varied in function of cathodic cage configuration. The plasma efficiency in the heat transfer was estimated by the ratio between the power supplied in the system (electric power) and the average of the species

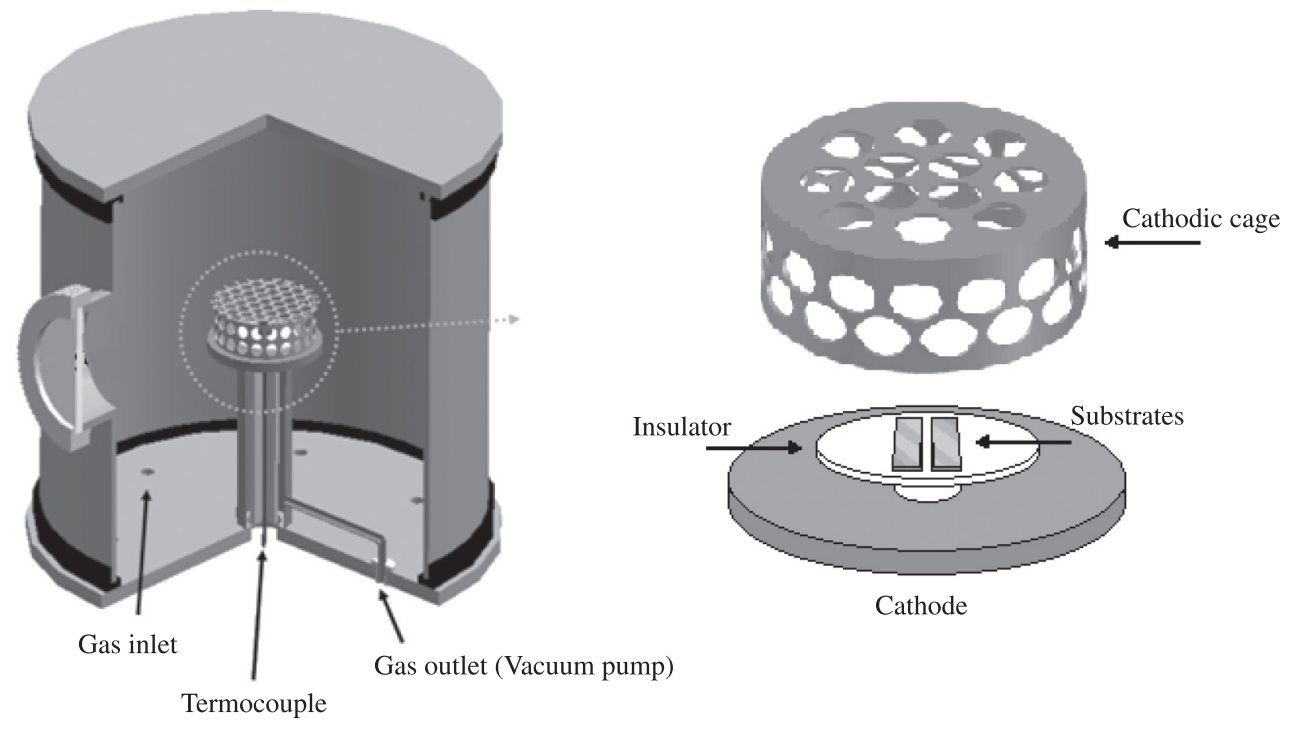

Figure 1. Schematic illustration of plasma reactor in cathodic cage configuration.

Table 1. Experimental conditions used in this study.

\begin{tabular}{|c|c|c|c|c|c|c|c|}
\hline \multirow[t]{2}{*}{ Sample } & \multirow[t]{2}{*}{ Current (A) } & \multirow{2}{*}{$\begin{array}{c}\text { Voltage } \\
\text { (V) }\end{array}$} & \multirow{2}{*}{$\begin{array}{c}\text { Power } \\
\text { (W) }\end{array}$} & \multirow{2}{*}{$\begin{array}{c}\text { Cage height } \\
(\mathrm{mm})\end{array}$} & \multirow{2}{*}{$\begin{array}{l}\text { Hole diameter } \\
\qquad(\mathbf{m m})\end{array}$} & \multicolumn{2}{|c|}{ Number of holes } \\
\hline & & & & & & Wall & Top \\
\hline $\mathrm{L}_{1} \mathrm{~T}_{4} \mathrm{~F}_{12}$ & 0.30 & 860 & 258 & 34 & 12 & 16 & 8 \\
\hline $\mathrm{L}_{1} \mathrm{~T}_{8} \mathrm{~F}_{12}$ & 0.31 & 820 & 254 & 34 & 12 & 16 & 12 \\
\hline $\mathrm{L}_{2} \mathrm{~T}_{4} \mathrm{~F}_{12}$ & 0.33 & 811 & 267 & 45 & 12 & 31 & 8 \\
\hline $\mathrm{L}_{2} \mathrm{~T}_{8} \mathrm{~F}_{12}$ & 0.36 & 878 & 316 & 45 & 12 & 31 & 12 \\
\hline $\mathrm{L}_{1} \mathrm{~T}_{8} \mathrm{~F}_{8}$ & 0.30 & 805 & 285 & 34 & 8 & 23 & 17 \\
\hline
\end{tabular}


energy (line intensities). These results indicated that the optimal configurations were the $\mathrm{L}_{1} \mathrm{~T}_{8} \mathrm{~F}_{8}$ and $\mathrm{L}_{1} \mathrm{~T}_{8} \mathrm{~F}_{12}$ cages.

The plasma efficiency increased as the amount of holes at the cage top increased. However, the highest efficiency was achieved when the lowest amount of holes was present at the sidewall of cage. Apparently, this result was contradictory, since it is expected that heating improve due to the higher area with hollow cathode effect. This result was justified by the farther distance between the pieces and the cage top, when the holes number in the sidewall was increased, because the heat from these holes was transferred to the chamber walls, to the inner and to the outer cage. Therefore, there was an appropriate height at $34 \mathrm{~mm}$ which the maximum efficiency was promoted due to combination of heating by hollow cathode effect and distance between the sample and the cage top.

The XRD patterns of deposited films at different cage configurations (Figure 4) exhibited two peaks at $37.3^{\circ}$ and $43.3^{\circ}$ corresponding to $\delta$-TiN (111) and $\delta$-TiN (200), respectively. The most intense TiN peak was observed at the $\mathrm{L}_{1} \mathrm{~T}_{8} \mathrm{~F}_{12}$ and $\mathrm{L}_{1} \mathrm{~T}_{8} \mathrm{~F}_{8}$ cage configuration. On the other hand, the $\mathrm{L}_{1} \mathrm{~T}_{4} \mathrm{~F}_{12}$ configuration exhibited the lowest deposition rate evidenced by low signal and high noise ratio.

Table 2 shows $I_{H} \alpha / I_{A r}$ line intensity values obtained from OES spectra (Figure 3), the TiN (200) peak intensity (Figure 4) and roughness values (Figure 5). There was a correlation between the luminous intensity of $\mathrm{H} \alpha$ species

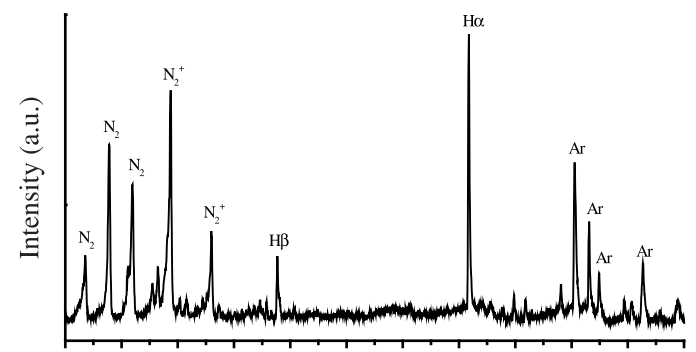

300350400450500550600650700750800850 Wavelenght (nm)

Figure 2. Plasma spectra obtained during deposition process at $\mathrm{L}_{1} \mathrm{~T}_{8} \mathrm{~F}_{12}$ configuration.



Figure 3. Luminous intensities of plasma active species at different cage configurations (bars) and values of the power supplied to keep the system at $450{ }^{\circ} \mathrm{C}$ (black dots). and the grown film characteristics. The highest deposition rate, (demonstrated by the intensity of TiN (200) diffraction peak) occurred when the $I_{H} \alpha / I_{A r}$ ratio was highest. Therefore the $\mathrm{H} \alpha$ species plays a key role in the deposition rate of $\mathrm{TiN}$, similar to literature reports ${ }^{18-21}$ : there was an increasing in deposition rate since the hydrogen reduced the presence of superficial oxides on the cage (cage poising), promoting a formation of more stoichimonetry film.

Furthermore, it was possible notice (Table 2) that the increasing in the number of holes in the sidewall promoted a reduction of film roughness, which was directly related to the decreasing of sputtering rate on the substrate, seeing as the increasing of the distance between the pieces and the cage top reduced the probability plasma particles collide with the substrate.

The few variations in refraction index and extinction coefficient (Figure 6) were related to different microstructure, because the refraction index vary in function of thickness,

Table 2. Luminous intensity of $\mathrm{H} \alpha$ species, characteristics of the crystal structure and topography of films deposited at different cage configuration.

\begin{tabular}{lcccc}
\hline \multirow{2}{*}{$\begin{array}{c}\text { Cage } \\
\text { configuration }\end{array}$} & $\mathbf{I}_{\mathbf{H}} \alpha / \mathbf{I}_{\text {Ar }}$ & $\begin{array}{c}\text { Intensity } \\
\delta \text {-TiN (200) }\end{array}$ & \multicolumn{2}{c}{ Roughness } \\
\cline { 4 - 6 } & & & Ra & Rms \\
\hline $\mathrm{L}_{1} \mathrm{~T}_{8} \mathrm{~F}_{12}$ & 53643 & 6676 & 4.27 & 3.53 \\
$\mathrm{~L}_{2} \mathrm{~T}_{8} \mathrm{~F}_{12}$ & 44900 & 3862 & 1.77 & 2.24 \\
$\mathrm{~L}_{1} \mathrm{~T}_{4} \mathrm{~F}_{12}$ & 41989 & 2520 & 3.66 & 2.95 \\
$\mathrm{~L}_{1} \mathrm{~T}_{8} \mathrm{~F}_{8}$ & 46629 & 6118 & 5.35 & 6.61 \\
\hline
\end{tabular}

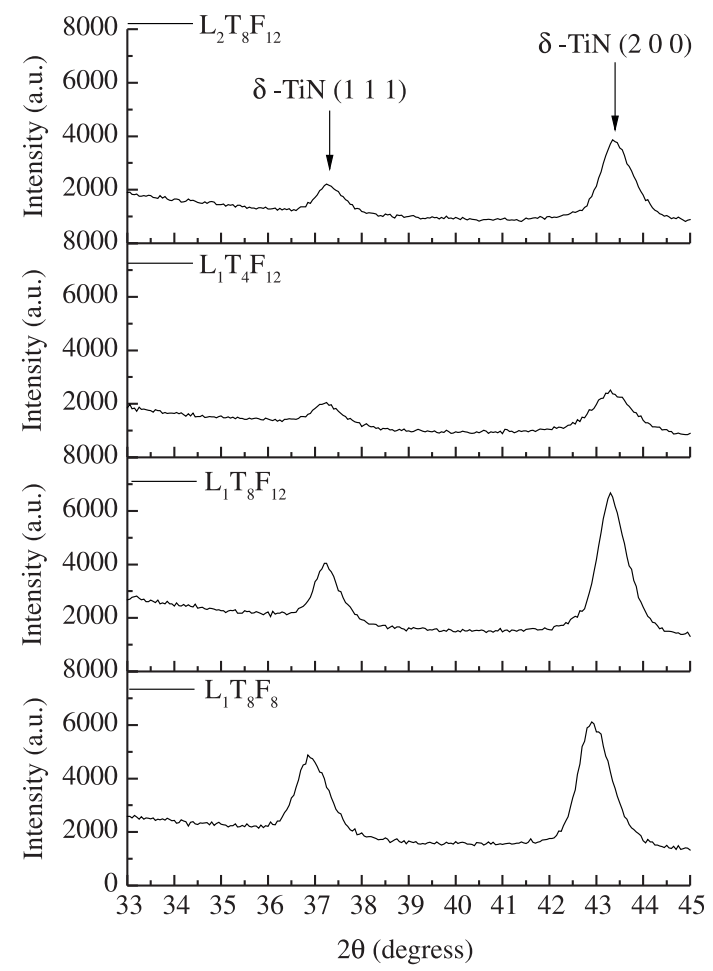

Figure 4. X-ray pattern for films deposited at different cage configurations. 


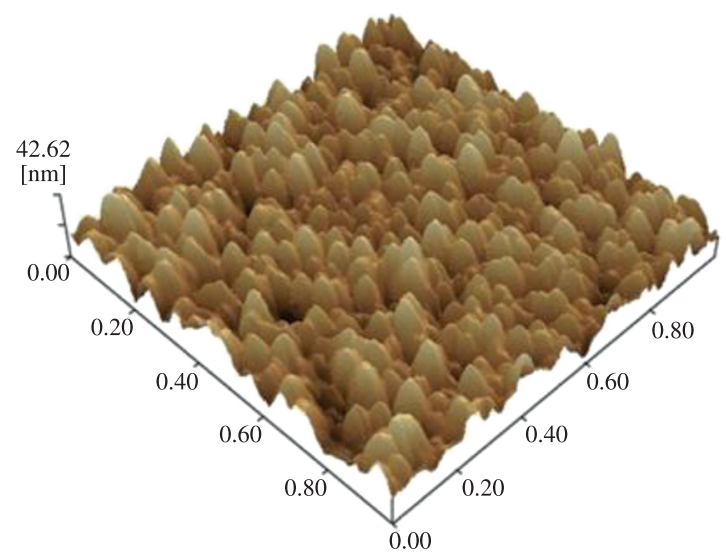

(a)

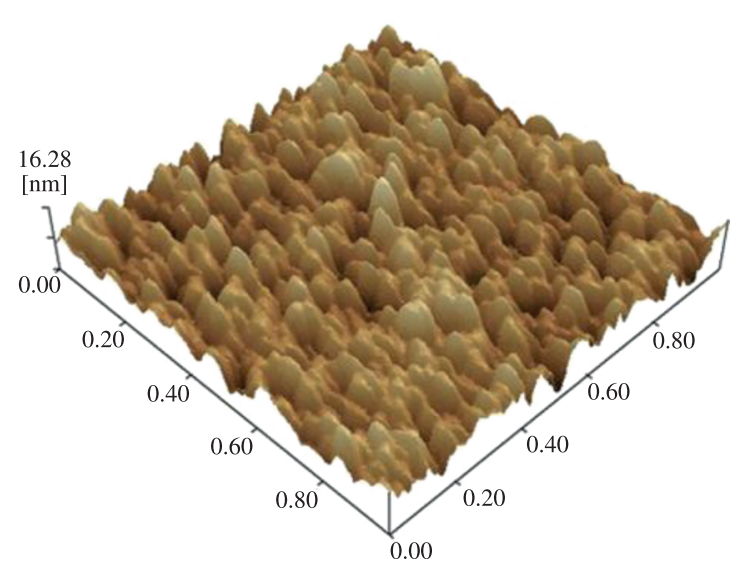

(c)

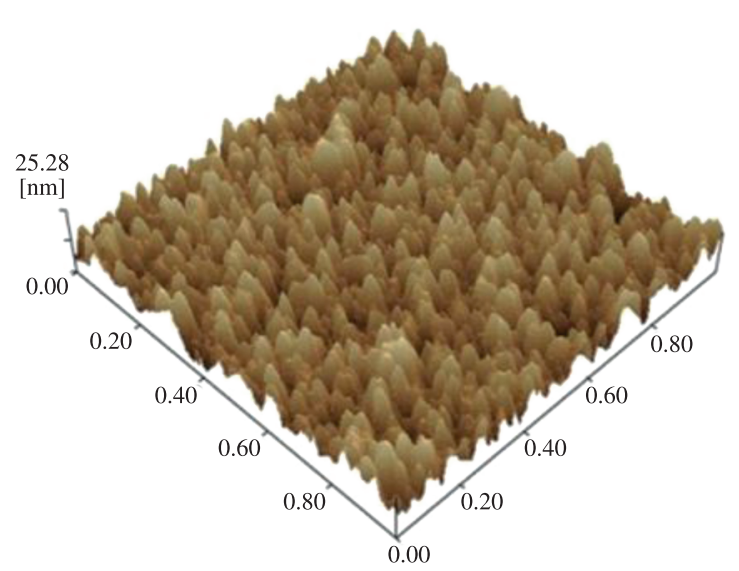

(b)



(d)

Figure 5. Nanotopography of the TiN films grown at (a) $\mathrm{L}_{1} \mathrm{~T}_{8} \mathrm{~F}_{8}$, (b) $\mathrm{L}_{1} \mathrm{~T}_{8} \mathrm{~F}_{12}$, (c) $\mathrm{L}_{2} \mathrm{~T}_{8} \mathrm{~F}_{12}$ and (d) $\mathrm{L}_{1} \mathrm{~T}_{4} \mathrm{~F}_{12}$ cage configurations.

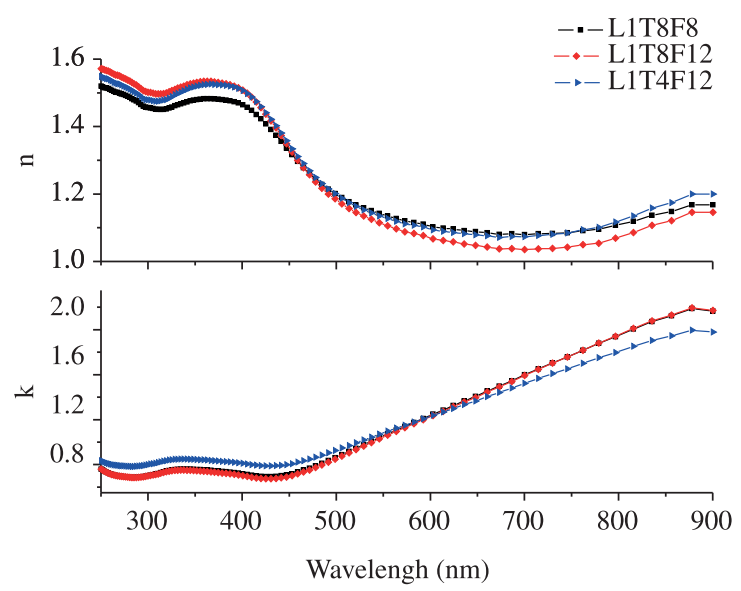

Figure 6. Dispersion plots, real part $\mathrm{n}(\lambda)$ and imaginary part $\mathrm{k}$ $(\lambda)$, obtained by spectral ellipsometry for film deposited at three different cage configurations.

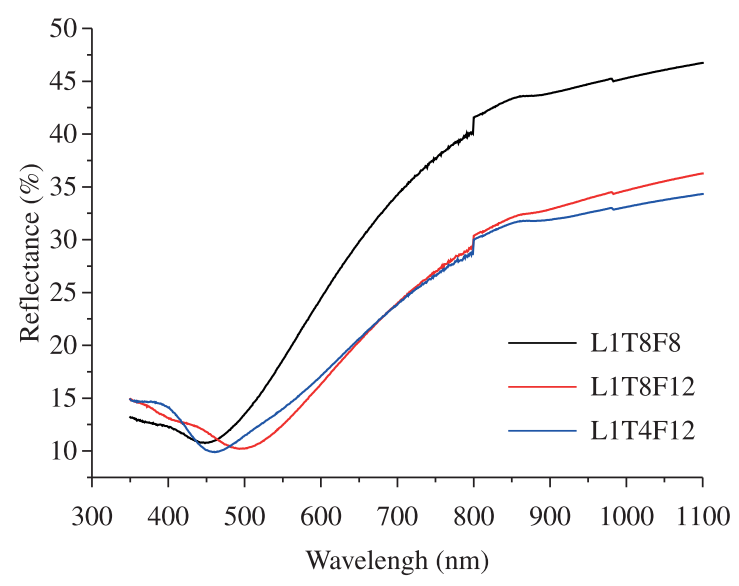

Figure 7. Spectra of light reflectance for films obtained at different cage configurations. 




Figure 8. Transmittance spectra for films obtained at different cage configurations.

chemical composition and porosity ${ }^{22,23}$. Moreover, those variations in refraction index resulted in reflectance (Figure 7) and transmittance spectra (Figure 8) modifications.

The transmittance values were different for films deposited at each cage configuration (Figure 8). The lowest transmittance indicated that there was the highest thickness since the crystal phase formed was almost the same for every condition as evidenced by X-Ray pattern (Figure 4). These results accorded to other results obtained by optical emission spectroscopy and X-Ray diffraction:

\section{References}

1. Sousa RRM, De Araújo FO, Ribeiro KJB, Da Costa JAP, Sousa RS and Alves Junior C. Uniformity of temperature in cathodic cage technique in nitriding of austenitic stainless steel AISI 316. Surface Engineering. 2008; 24:313-318. http:// dx.doi.org/10.1179/174329408X326830

2. Ahangarani S, Sabour AR, Mahbouni F and Shahrabi T. The influence of active screen plasma nitriding parameters on corrosion behavior of a low-alloy steel. Alloys and Compounds. 2009; 484:222-229. http://dx.doi.org/10.1016/j. jallcom.2009.03.161

3. Ribeiro KJB, Sousa RRM, De Araújo FO, Brito RA, Barbosa JCP and Alves Junior C. Industrial application of AISI 4340 steel treated by in cathodic cage plasma nitriding technique. Materials Science and Engineering A. 2008; 479:142-147. http://dx.doi.org/10.1016/j.msea.2007.06.033

4. Alves Junior C, De Araújo FO, Ribeiro KJB, Costa JAP, Sousa RRM and Sousa RS. Use of cathodic cage in plasma nitriding. Surface and Coatings Technology. 2006; 201:2450-2454. http:// dx.doi.org/10.1016/j.surfcoat.2006.04.014

5. Nishimoto A, Bell TE and Bell T. Feasibility study of active screen plasma nitriding of titanium alloy. Surface Engineering. 2010; 26:79-84. http://dx.doi.org/10.1179/0267 08409X12454193831760

6. Kauling AP, Soares GV, Figueroa CA, De Oliveira RVB, Baumvol IJR, Giacomelli C et al. Polypropylene surface modification by active screen plasma nitriding. Materials Science and Engineering C. 2009; 29:63-366. http://dx.doi. org/10.1016/j.msec.2008.07.002 the films obtained at $\mathrm{L}_{1} \mathrm{~T}_{8} \mathrm{~F}_{8}$ and $\mathrm{L}_{1} \mathrm{~T}_{8} \mathrm{~F}_{12}$ cage configuration had the lowest transmittance values, thus the highest deposition rates.

\section{Conclusions}

Based on the experimental results of this study, the following conclusions can be drawn:

- TiN films can be grown on glass substrates by cathodic cage discharge;

- The deposition rates, microstructures and optical properties of grown films were influenced by the gas species density and cage configuration;

- The $\mathrm{L}_{1} \mathrm{~T}_{8} \mathrm{~F}_{8}$ and $\mathrm{L}_{1} \mathrm{~T}_{8} \mathrm{~F}_{12}$ cage configurations, in this order, were the most efficient when the ratio between supplied power and average energy of the species was considered;

- In general, configurations with more holes at the top of the cage exhibited higher efficiency. However, it was not observed when the holes at sidewall of the cage were more numerous. Actually, in this case, the efficiency was lower;

- There was a correlation between the luminous intensity of $\mathrm{H} \alpha$ species and the characteristics of the grown film. The highest deposition rate and the highest crystallinity were obtained with the highest $\mathrm{I}_{\mathrm{H}} \alpha / \mathrm{I}_{\mathrm{Ar}}$ ratio; and

- The optical properties varied in function of microstructure and deposition rate of grown film.

7. Dong Y, Li X, Tian L, Bell T, Sammons RL and Dong H. Towards long-lasting antibacterial stainless steel surfaces by combining double glow plasma silvering with active screen plasma nitriding. Acta Biomaterialia. 2011; 7:447-457. http:// dx.doi.org/10.1016/j.actbio.2010.08.009

8. Gallo SC and Dong H. On the fundamental mechanisms of active screen plasma nitriding. Vacuum. 2010; 84:321-325. http://dx.doi.org/10.1016/j.vacuum.2009.07.002

9. Nishimoto A, Nagatsuka K, Narita R, Nii H and Akamatsu K. Effect of the distance between screen and sample on active screen plasma nitriding properties. Surface and Coatings Technology. 2010; 205:S365-S368. http://dx.doi.org/10.1016/j. surfcoat.2010.08.034

10. Sousa RRM, Araújo FO, Ribeiro KJB, Mendes MWD, Da Costa JAP and Alves Junior C. Cathodic cage nitriding of samples with different dimensions. Materials Science and Engineering A. 2007; 465:223-227. http://dx.doi.org/10.1016/j. msea.2007.03.007

11. Peng Z, Miao H, Qi L, Yang S and Liu C. Hard and wearresistant titanium nitride coatings for cemented carbide cutting tools by pulsed high energy density plasma. Acta Materialia. 2003; 51:3085-3094. http://dx.doi.org/10.1016/ S1359-6454(03)00119-8

12. Roquiny P, Bodart F and Terwagne G. Colour control of titanium nitride coatings produced by reactive magnetron sputtering at temperature less $100^{\circ} \mathrm{C}$. Surface and Coatings Technology. 1999; 116(119):278-283. http://dx.doi. org/10.1016/S0257-8972(99)00076-6

13. Smith GB, Ben-David A and Swift PD. A new type of TiN coating combining broad band visible transparency and solar 
control. Renewable Energy. 2001; 22:79-84. http://dx.doi. org/10.1016/S0960-1481(00)00071-9

14. Cheng Y and Zheng YF. Formation of TiN on biomedical TiNi shape memory alloy by PIII. Materials Science Engineering A. 2006; 434:99-104. http://dx.doi.org/10.1016/j. msea.2006.07.027

15. Wittmer M, Noser JR and Melchior H. Characteristics of TiN gate metal-oxide-semiconductor field effect transistors. Journal of Applied Physics. 1983; 54:1423-1428. http://dx.doi. org/10.1063/1.332167

16. Sankar MB, Pal AR, Bailung $H$ and Cuthia J. Optimization of plasma parameters for high hate deposition of titanium nitride films as protective coating on bell-metal by reactive sputtering in cylindrical magnetron device. Applied Surface Science. 2008; 254:5760-5765. http://dx.doi.org/10.1016/j. apsusc.2008.03.047

17. Tamaki M, Tomii Y and Yamoto M. The role of hydrogen in plasma nitriding: Hydrogen behavior in the titanium nitride layer. Plasma and Ions. 2000; 3:33-39. http://dx.doi. org/10.1016/S1288-3255(00)00108-8

18. Safi I. Recent aspects concerning DC reactive magnetron sputtering on thin films: a review. Surface and Coatings Technology. 2000; 127:203-217. http://dx.doi.org/10.1016/ S0257-8972(00)00566-1
19. Figueroa CA and Alvarez F. On the hydrogen etching mechanism in plasma nitriding of metals. Applied Surface Science. 2006; 253:1806-1809. http://dx.doi.org/10.1016/j. apsusc.2006.03.015

20. Priest JM, Baldwin MJ and Fewel MP. The action of hydrogen in low pressure r.f. - plasma nitriding. Surface and Coatings Technology. 2001; 145:152-163. http://dx.doi.org/10.1016/ S0257-8972(01)01311-1

21. Sharma MK, Saikia BK, Phukan A and Ganguli B. Plasma nitriding of austenic stainless steel in $\mathrm{N}_{2}$ and $\mathrm{N}_{2}-\mathrm{H}_{2}$ dc pulsed discharge. Surface and Coatings Technology. 2006; 201:24072413. http://dx.doi.org/10.1016/j.surfcoat.2006.04.006

22. Jeyachandran YL, Narayandas SK, Mangalaraj D, Areva S and Mielkczarski JA. Properties of titanium nitride films prepared by direct current magnetron sputtering. Materials Science Engineering A. 2007; 445(446):223-236. http://dx.doi. org/10.1016/j.msea.2006.09.021

23. Duan G, Zhao G, Wu L, Lin X and Han G. Structure, electrical, optical properties of $\mathrm{TiN}_{\mathrm{x}}$ films by atmospheric pressure chemical vapor deposition. Applied Surface Science. 2011; 257:2428-2431. http://dx.doi.org/10.1016/j. apsusc.2010.11.180 